\title{
SIN FACUNDO NO HAY NUNCA MÁS. TRAYECTORIAS, CONTIENDAS MORALES Y OPACIDADES EN LA PRODUCCIÓN SOCIAL DE UNA VÍCTIMA "NO INOCENTE" EN CÓRDOBA (ARGENTINA)
}

\author{
Without Facundo there is no "Nunca Más". Trajectories, moral strives and opacities \\ in the social production of an "non-innocent" victim in Cordoba (Argentina)
}

\author{
Natalia Bermúdez * \\ *IDACOR, CONICET, Universidad Nacional de Córdoba (Argentina) \\ natibermudez@yahoo.com.ar
}

\section{Palabras clave \\ Desaparición \\ Familia \\ Moralidades \\ Identidades \\ Argentina}

\section{Keywords}

Disappearance

Family

Moralities

Identities

Argentina

\begin{abstract}
Resumen
¿Quiénes quedan fuera de las organizaciones que se constituyen para demandar justicia?, ¿cómo se construyen las clasificaciones y las jerarquías sociales en torno a los familiares de víctimas?, ¿de qué modos se logran inscribir ciertas muertes y desapariciones como un problema y un drama colectivo en Argentina? En este artículo muestro cómo se fue configurando políticamente la desaparición de un joven proveniente de sectores populares en la ciudad de Córdoba (Argentina) y los reclamos de su familia, a partir del análisis de las trayectorias implicadas y del agenciamiento particular de las redes que se entramaron con organismos de derechos humanos. En el marco de este proceso analizo, por un lado, el modo en que el parentesco pasa a constituirse como un principio organizador que habilita a fundar las articulaciones de repertorios y demandas entre un pasado reciente y un presente democrático. Y, por otro, indago cómo la desaparición se fue legitimando en diversos espacios sociales, académicos y políticos, consiguiendo trascender la construcción del caso judicial, ligado a una violencia horizontal de orden privado. Más allá del dictamen de la Justicia, la desaparición, como muerte inconclusa, (re)actualiza constantemente la lucha y vuelve a colocar el acento sobre la responsabilidad de las agencias del Estado. Por último, a partir del recorrido etnográfico y desde un recorte de clase, problematizo las implicancias de las inclusiones, exclusiones y fronteras que las categorías de parentesco instituyen.
\end{abstract}

\section{Abstract}

Who are left out of the organizations that are constituted to demand justice? How are classifications and social hierarchies built around the relatives of victims? In what ways are some deaths and disappearances recorded as a problem and collective drama in Argentina? In this article, I show how the disappearance of a young man from the popular sectors in the city of Córdoba (Argentina) and the claims of his family began to take shape politically, by analyzing the trajectories involved and the particular arrangement of the networks with human rights organizations. In the framework of this process I analyze, on the one hand, the way in which kinship happens to be constituted as an organizing principle that enables to establish the articulations of repertoires and demands between a recent past and a democratic present. And, on the other hand, I wonder how the disappearance was legitimized in various social, academic and political spaces, managing to transcend the construction of the judicial case, linked to horizontal violence, private order. Beyond the opinion of Justice, the disappearance, as an unfinished death, constantly updates the struggle and re-emphasizes the responsibility of state agencies. Finally, based on ethnographic work and from a class perspective, I problematize the implications of the inclusions, exclusions and frontiers that the categories of kinship institute.

Bermúdez, N. (2017). Sin Facundo no hay Nunca Más. Trayectorias, contiendas morales y opacidades en la producción social de una víctima "no inocente" en Córdoba (Argentina). Papeles del CEIC, vol. 2017/2, papel 178, CEIC (Centro de Estudios sobre la Identidad Colectiva), UPV/EHU Press, http://dx.doi.org/10.1387/pceic.17651 


\section{INTRODUCCIÓN ${ }^{1}$}

Cada vez resultan más fructíferos los trabajos que nos advierten sobre la relevancia que ocupa el parentesco para quienes reclaman contra la violencia estatal o contra la impunidad y demandan justicia o mayor responsabilidad por parte del Estado en tiempos democráticos. Algunos referentes de ello son la Comisión de Familiares de Víctimas de la Violencia Institucional (Cofavi) (Gingold, 1996), la Asociación Madres del Dolor (Claps, 2007), la Coordinadora contra la Represión Policial e Institucional (Correpi) (Tiscornia, 2004 y 2005; Pita, 2004 y 2010), Familiares de Cromañón (Zenobi, 2014) y las asociaciones civiles Madres de Dolor (Rebollar, 2013) y Padres del Dolor (Bermúdez, 2011). Esta relevancia se produce en un marco más amplio de consolidación de la lucha de las asociaciones y movimientos de derechos humanos que denunciaron el accionar del terrorismo de Estado en Argentina, tal como ha sido problematizando por diversas autoras (Pita, 2005 y 2010; Da Silva Catela, 2008; Vecchioli, 2005; entre otros) ${ }^{2}$. Es precisamente dentro de estos marcos que parece necesario analizar los entramados sociales, culturales y políticos en los que las víctimas resultan socialmente producidas y legitimadas.

En trabajos anteriores (Bermúdez, 2014 y 2016) he procurado dar cuenta de las modalidades de acceso a la condición de "activista familiar" ${ }^{3}$ con especial atención en las disputas, exclusiones y contiendas morales que atraviesan las víctimas de muertes violentas ocurridas en sectores populares. Coincido en este sentido con Sarti (2009) cuando advierte que la producción de un determinado tipo de víctima, al mismo tiempo que permite visibilizar ciertas lógicas, contribuye a esconder otras manifestaciones que no resultan identificadas con ellas y que valdría la

\footnotetext{
${ }^{1}$ Agradezco muy especialmente a los evaluadores de este texto por sus respetuosos y muy iluminadores aportes.

${ }^{2}$ Cabe señalar, al mismo tiempo, que existen otras organizaciones que no necesariamente apelan al parentesco para la representación pública, como la Correpi, el Centro de Estudios Legales y Sociales (CELS) o, en Córdoba, La Coordinadora Antirrepresiva. Para un análisis sobre ello ver Vecchioli (2005).

${ }^{3}$ Me he basado en el trabajo de María Pita, quien analiza la politización de casos de violencia policial o institucional a través de la intervención de los familiares de las víctimas. La autora pone énfasis en una diferencia nodal en el argumento de su tesis y que retomo aquí, "al hablar de familiares no se está haciendo referencia a todas aquellas personas ligadas por lazos de parentesco con las víctimas de esta violencia, sino a aquellas personas que ligadas por lazos de parentesco con las víctimas, a través de la denuncia y la protesta, se han convertido en un tipo particular de activista político" (2010: 8).
} 
pena abordar. Me he preguntado entonces quiénes quedan por fuera de las organizaciones que se constituyen para demandar justicia, cómo se construyen las clasificaciones y las jerarquías sociales en torno a los familiares, cuáles son las prácticas que desde la academia consideramos como "políticas" (Bermúdez, 2016) y a través de qué modos se logran inscribir ciertas muertes como un problema y un drama colectivo.

Partir del supuesto de que las articulaciones entre repertorios de demandas vinculados a un pasado político reciente y la actual vida democrática no se producen linealmente ni están exentas de tensiones y disputas implica reconocer, por un lado, los desafíos con los que se encuentran actualmente los organismos de derechos humanos (Jelin, 2005; Sikkink, 1999; entre otros) y la necesidad, por otro, de privilegiar en nuestras investigaciones visiones menos normativas y sociocéntricas de la política y de los movimientos sociales en América Latina. En este marco, considero que el recorte de clase puede convertirse en un prisma bueno para pensar situacionalmente tanto las barreras y fronteras como las relaciones y pasajes que articulan diversos grupos, clases y mundos, en vez de darlos por sentado o, incluso, de invisibilizarlos (Fonseca, 2005; Ortner, 1995; Zaluar, 1999).

Los abordajes sobre la primacía del vínculo familiar y el reconocimiento de los familiares como actores legítimos para la denuncia de las atrocidades cometidas por el terrorismo de Estado en Argentina nos remontan a algunas investigaciones pioneras como las de Filc (1997), Vecchioli (2005), Jelin (2007), Da Silva Catela (2001), entre otras.

Ludmila da Silva Catela ha analizado la categoría "familiar de desaparecido" en los homenajes y rituales del 24 de marzo desde las jerarquías que se establecen y señala que: "los lazos de sangre y las metáforas de parentesco son manipuladas como poderosos medios emotivos por parte de los diferentes grupos, como formas de asociación, o como marcadores de los límites inclusivos o excluyentes" (2001: 73). Por su parte, Virginia Vecchioli ha señalado que "los lazos individuales de consanguinidad entre las víctimas y sus familiares son extendidos a todos los que participan de esta militancia" (2005: 6), por lo que consiguen conformar comunidades políticas más amplias. Para Elizabeth Jelin, en cambio, Madres, Abuelas, Hijos, Herman@s de Desaparecidos por la Verdad y la Justicia, Familiares son organizaciones que "entran en la esfera pública no como metáforas o imágenes 
simbólicas de los lazos familiares, sino en un sentido literal (y biológico) de las relaciones de parentesco" (2007: 44).

Más recientemente, María Pita aborda casos de violencia policial o institucional en Buenos Aires a través de la intervención de los familiares de las víctimas, devenidos muchas veces en "activistas familiares". La autora muestra cómo la protesta que desarrollan permite un doble movimiento: por un lado, "re-inscribir en la humanidad a estos muertos revirtiendo su condición de seres matables" $y$, por otro, impugnar esa condición, para habilitar "la politización de esas muertes" (2010: 115). Resultan también inspiradores para este trabajo los últimos estudios de Pita sobre la violencia institucional como categoría política y su análisis de los activismos locales (2016), en la medida en que ponderan la productividad de los usos de esta categoría en el presente.

En esta misma vía podemos encontrar una serie de trabajos que se vienen desarrollando en Brasil. Entre ellos, la investigación de Fabio Araújo (2007) parte de una masacre en la que desaparecen once jóvenes provenientes de territorios criminalizados, y describe en detalle la lucha de las llamadas Mães de Acari, convertida ciertamente en emblemática por su repercusión internacional. Por su parte, Vianna y Farias (2011) ponen el acento en la expresión de dolor por parte de familiares de personas muertas por la Policía Militar en Río de Janeiro. Se detienen en el trabajo simbólico efectuado por los familiares para legitimar sus luchas, vinculado a una tarea argumentativa que consiste en limpiar moralmente a las víctimas. Las autoras recalcan la importancia de que todos los asistentes a estos actos devienen "madres", incluso los padres allí presentes. Al abordar las movilizaciones de los familiares de los "meninos de Altamira", Paula Lacerda (2014) muestra cómo las narrativas de las víctimas se convierten en actos políticos y sus caminhadas constituyen una parte dolorosa pero también fundante de la transformación de los "crímenes" en "casos".

Específicamente, en este artículo me interesa problematizar los modos en que se fue configurando la desaparición de Facundo, un joven proveniente de sectores populares en la ciudad de Córdoba y los reclamos de su familia, a partir del análisis de las trayectorias implicadas y del agenciamiento particular de las redes de relaciones sociales que se entramaron a partir de ella, especialmente en torno a los organismos de derechos humanos. Mostrar casos emblemáticos partiendo de los procesos en los que los familiares devienen -o no- en víctimas, resulta 
un ejercicio prolífico toda vez que puede develarnos algunos cuestionamientos sobre categorias aparentemente instituidas y sobre los modos en que las luchas resultan más o menos consagradas ${ }^{4}$. Abordaré entonces el proceso por el cual Viviana, madre de Facundo, se convierte en activista familiar y por el que el parentesco en tanto hecho social $^{5}$ pasa a constituirse en un principio organizador que habilita a fundar las articulaciones, rupturas y continuidades entre un pasado reciente y un presente democrático.

Las reflexiones que aquí desarrollaré surgen de una investigación etnográfica y comparativa que llevo a cabo desde 2007, que aborda redes de relaciones familiares, sociales y políticas vinculadas a muertes en contextos de violencia, en villas y barrios empobrecidos económicamente de la ciudad de Córdoba, Argentina. Acompañar a familias y vecinos a los cementerios, marchas y misas en las fechas conmemorativas, así como estar presente en charlas y reuniones en calles, patios y viviendas fueron las actividades más importantes del trabajo de campo. He realizado además numerosas entrevistas en profundidad a madres y padres de jóvenes muertos producto de la violencia policial, de la inseguridad o de los denominados ajustes de cuentas para diversos proyectos académicos en los que participo.

Este escrito también forma parte de actividades de intervención entre la universidad y distintas organizaciones ${ }^{6}$ con familiares de víctimas para la creación de una muestra de imágenes. Titulada "Entre altares y pancartas. Imágenes, luchas y memorias de la violencia institucional en

\footnotetext{
${ }^{4}$ Otro caso que me interesa mencionar es el de Raquel Wittis, madre de Mariano, quien fuera tomado como rehén en el asalto a un banco y fuera fusilado por la policía de la provincia de Buenos Aires en el año 2000. Raquel se unió en el reclamo de justicia a la madre del captor, también fusilado por la policía. Primero integró Madres del Dolor y luego la Secretaría de Derechos Humanos de la Nación. Considero que alianzas como esta permiten discutir las fronteras instituidas socialmente entre víctimas y victimarios $e$ invitan a cuestionar los sentidos hegemónicos que le vienen siendo adjudicadas en las últimas décadas a nociones como inseguridad o violencia.

${ }^{5}$ La conceptualización de las relaciones de parentesco que desarrollo se basa en las lecturas de Bourdieu (2007), Schneider (1968) y Abreu Filho (1982).

${ }^{6}$ Algunos de los familiares que participan de la muestra pertenecen principalmente a la Coordinadora Antirrepresiva y a la Mesa de Trabajo por los Derechos Humanos, ambas en Córdoba (Argentina). Presentaré a la Mesa en detalle más adelante. La Coordinadora fue creada en 2006 y, tal como señala en su espacio virtual, "con compañeros y compañeras jóvenes que a partir de los acontecimientos de 2001 empezaron a pensar, ansiar y vivir en una Argentina distinta...". Ver: http://antirrepresiva.blogspot.com.ar/. Última consulta: 01/02/2017.
} 
Córdoba", la muestra tiene una modalidad itinerante y congrega casos producidos desde el retorno a la democracia hasta el presente. El objetivo principal consiste en visibilizar tanto las actividades vinculadas a lo que los familiares llaman "la lucha", como aquellas prácticas conmemorativas y narrativas desplegadas en los espacios privados y públicos, especialmente en torno a altares y grutas. A partir de estas prácticas, los familiares confrontan las significaciones hegemónicas que estigmatizan las muertes de los jóvenes, posibilitando narrarlas "desde abajo" y dotándolas de las propias emociones, versiones y experiencias que movilizan en torno a ellas. Como se verá más adelante, la incorporación del caso de Facundo en la muestra implicó una serie de desafíos.

\section{FACU, EL RUBIO DEL PASAJE}

Al Rubio del Pasaje le gustaba - mucho- la música de cuarteto. Hasta tenía su propia banda. Si bien la Mona Jiménez, al igual que para muchos cordobeses, era su máximo ídolo, el Rubio frecuentaba también otros bailes, entre los que se encontraban los de Damián Córdoba, probablemente por su amistad con uno de los integrantes del grupo. Era imposible no darse cuenta de las preferencias del Rubio al entrar en su habitación aquella tarde de noviembre del año 2012, en ocasión de la entrevista que le hariamos a Viviana, su madre, para la muestra de imágenes. En ese momento conocía a Viviana a través de los medios de comunicación. Poco a poco se iría convirtiendo en una figura pública. Estas circunstancias marcaban ciertas diferencias respecto de la mayoría de los familiares con los que venía trabajando y que, aun perteneciendo a diversas organizaciones sociales, no habian alcanzado la misma preeminencia como activistas ${ }^{7}$; o con otros tantos casos, todavía menos conocidos, a los que no hubiera podido acceder sin la intermediación de sus vecinos.

\footnotetext{
${ }^{7}$ Especialmente la Mesa de Trabajo por los Derechos Humanos a la que pertenece Viviana, pero también la Coordinadora Antirrepresiva y la Campaña Contra la Violencia Institucional, nuclean gran parte de los casos vinculados a víctimas de violencia policial o institucional de los sectores populares cordobeses. La Campaña se presentó públicamente en 2012 y, según sostiene, funciona a través de una red de abogados y estudiantes de derecho, promotores y voluntarios, con un significativo trabajo territorial. Algunas actividades son co-coordinadas con la Mesa de Trabajo por los Derechos Humanos.
} 
La casa de un barrio del este de la ciudad de Córdoba, compuesta por pocos ambientes, se encontraba en un pasaje, tal como quedara plasmado en el apodo de Facundo. Desde la entrada se podía ver una mesa para dos o tres comensales y de allí dos habitaciones más. Palermo ${ }^{8}$, el perro del Rubio, entraba y salía constantemente. Viviana nos hizo pasar sin demasiados preámbulos a donde se llevaría a cabo la entrevista: su cuarto, conservado tal cual lo dejara Facu por última vez. Entramos tratando de no tocar nada. Me senté sobre la cama, al lado de Viviana.

Recortes de diarios, revistas, un sinnúmero de afiches de Boca Juniors y escritos a su hija recién nacida apenas dejaban ver las paredes donde estaban colgados. A cierta incomodidad por tanta "presencia" del Rubio se sumó el olor a pintura que Viviana decía aún sentir en los pantalones de obrero que acondicionó sobre la cama frente a nosotros. Ese mismo que usaría horas antes de desaparecer.

Aquella noche de febrero, después de trabajar todo el día, cenó con su novia y su mamá. Se bañó y se fue al baile de Damián, en el Estadio del Centro. No llevó su celular, porque estaba descargado. Sus amigos lo vieron a la salida y no se supo más de él. Apenas Viviana se dio cuenta de que Facundo no volvía, sospechó de la policía, porque ya había sido detenido tres veces por contravenciones ${ }^{9}$. Portación de barrio, apellido, rostro y vestimenta resultan los etiquetamientos más frecuentes que operan como mecanismos de exclusión sobre el uso y la experimentación de la ciudad, de tal manera que gran parte de estos jóvenes no consiguen desplazarse sin ser detenidos por la policía ${ }^{10}, \mathrm{o}$ al menos sin perder el anonimato. No es por casualidad que la denominada Marcha de la Gorra, organizada por el Colectivo de Jóvenes por Nuestros Derechos ${ }^{11}$ contra la violencia institucional y el entonces Ilamado Código

\footnotetext{
${ }^{8}$ El nombre hace alusión al jugador de fútbol boquense Martín Palermo, que el Rubio admiraba.

${ }^{9}$ La mayor cantidad de detenciones y controles policiales en la provincia se producían bajo los artículos 98, 53 y 45 del Código de Faltas - actual Código de Convivencia-, vinculados especialmente a la figura del merodeo. Organizaciones sociales, organismos de derechos humanos y diversos especialistas en el tema han denunciado la arbitrariedad de estas detenciones dirigidas casi exclusivamente hacia jóvenes provenientes de sectores populares.

${ }^{10}$ Ver: Coria y Etchichury (2010). Para problematizar sus implicancias, sugiero consultar: Brocca et al., 2013.

${ }^{11}$ Este colectivo de jóvenes se creó en 2007, según refieren, para organizarse "por la defensa de nuestros derechos y en contra del abuso policial". Esta organización es una de
} 
de Faltas, encuentra en el canto "No es merodeo, es paseo" un reclamo medular. El merodeo se ha convertido en la figura paradigmática de la Córdoba de los últimos años, aunque representa solo una parte de políticas de "seguridad" más amplias, complejas y no menos represivas.

Viviana nos cuenta:

Me despierto a las seis y no estaba en la pieza Facu. Llovía bastante ese día. Lo saco a Palermo y volvemos. Él hacía mucho ruido cada vez que Facu venía, pero esa madrugada durmió toda la noche. Me acuesto de nuevo. A eso de las diez y algo, me desperté con el sol fuerte en la cara, el que sale después de una lluvia fuerte. De ahi fue la preocupación porque no estaba. Ni me había mandado mensaje, aunque sea con otro celular.

Él en realidad iba a los bailes de la Mona, pero ya no iba porque más porque no podía disfrutar. Los mismos policías los paran, los presionan, y de tanta humillación es que los chicos reaccionan, y cuando reaccionan... pierden. Él tampoco iba al Estadio del Centro porque está cerca de la Central de Policía. Pero ese día estaba con unas amistades nuevas y fueron.

Yo empecé a buscar. Prendí el celular y encontré un mensaje de las seis y pico que decía: “¿dónde estás?" Fui a averiguar en los hospitales. Arranqué por ahí. Pero después fui directo a la comisaría porque a Facu lo habian detenido varias veces por el Código de Faltas. Pero Facu nunca tuvo problemas delictuales. No era choro, y con esto no quiero hacer diferencia con otros chicos. Pero no había forma de encasillarlo para cierta gente. Como me dijo en la marcha una persona: un choro menos. No. Nunca tuvo problemas. Y si él había cometido algún error, hacelo aparecer, júzgalo y condénalo. Pero con eso no quiero hacer diferencia con otros chicos. Por el Código de Faltas sí, porque él discutía y lo levantaban. Ya lo conocían que reaccionaba y entonces a propósito, los policías lo paraban.

Desde el principio la versión que sostuvo la policía decía que Facu era vendedor de drogas al menudeo, basándose en un mensaje de texto de su celular. Al parecer alguien del grupo musical le había pedido que vaya a comprar droga a cambio de llevarlo de gira. Ahora bien, lejos de ser una mera descripción que pudiera aportar a desentrañar los entramados

las principales promotoras de la Marcha de la Gorra, que se realiza todos los noviembres en el centro de la ciudad de Córdoba. 
del "caso", este señalamiento le adjudica una condición moral, naturalizada y reproducida por gran parte de los medios de comunicación. Cuando se hace referencia a los jóvenes, especialmente varones provenientes de los sectores populares cordobeses, siempre aparece algún tipo de acusación moral que permite depositar en la propia víctima la culpa por lo ocurrido (Segato, 2013).

Se trata de jóvenes estigmatizados en vida, y cuya desaparición o muerte los vuelve a colocar bajo esta misma condición. En otros trabajos he mostrado cómo se configuran las clasificaciones y jerarquías en torno a estos asuntos, y las repercusiones que tienen sobre la vida de las personas (Bermúdez, 2011). A los efectos de este, basta decir que una "víctima de inseguridad" es asumida socialmente como una víctima inocente, mientras que a aquellos que son asesinados en barrios y villas consideradas como zonas peligrosas, se les adjudica la condición de sospechosos y a sus muertes la de "ajuste de cuentas". Clasificaciones que imputan cierto merecimiento de la muerte, en la medida en que hacen referencia a las actividades ilegales de sus protagonistas, como la delincuencia y/o la venta y consumo de drogas. A la vez, y partiendo del supuesto de que los jóvenes asesinados pudieron haber estado cometiendo algún delito, la violencia policial o en lugares de encierro aparece legitimada para algunos sectores sociales (Bermúdez, 2016).

El juicio por la desaparición de Facundo se desarrolló en agosto del año 2015. Recuerdo que por entonces Viviana me había llamado por teléfono para preguntarme si podía conseguir un aula en la universidad para reunir alli a aquellos que la apoyaban, especialmente estudiantes universitarios de distintas agrupaciones políticas. "Familiares y amigos de Facundo" surgió así como un modo de nuclear a quienes estuvieran dispuestos a colaborar con las actividades vinculadas al juicio. Una de las tareas más importantes consistió, por ejemplo, en la difusión de un "diario", donde se mostraban más complejamente los pormenores de todo el proceso desde las propias versiones de la familia y de su abogado $^{12}$.

El resultado de esta instancia judicial ratificó las interpretaciones oficiales. Un joven de la zona este fue condenado a 12 años de prisión al

12 Para ver el "diario del juicio", consultar: http://sinfacundonohayjusticia.com/category/el-juicio-dia-x-dia/. Última consulta: 03/03/2017. 
ser considerado coautor y responsable del delito de homicidio, mientras que su hermano fue inimputable por tener 15 años de edad. Por su parte, un ex empleado municipal que estaba acusado de utilizar el horno del cementerio San Vicente para hacer desaparecer el cuerpo, fue absuelto $^{13}$. Hasta la fecha de escritura de este texto no se han encontrado evidencias del cuerpo de Facundo.

En efecto, estas conclusiones no lograron abarcar lo que tanto Viviana como diversas organizaciones venían denunciando desde la desaparición $^{14}$, esto es, la existencia de otros entramados más estructurales vinculados con el rol de los policias encargados de la seguridad del baile e incluso del cementerio donde supuestamente fuera llevado Facundo y en especial con las redes que forman parte de la economía ilegal en algunos de los barrios populares conocidos como "zona liberada".

El mapa de georeferenciación organizado por el Observatorio de Derechos Humanos de la UNC que marca el "Uso letal de la fuerza por parte de agentes estatales en Córdoba" se dirige a resaltar estas implicaciones. Allí se clasifica al caso de Facundo como desaparición, es decir, cuando:
"una persona ha sido reportada como tal y que existan sospechas de la participación de agentes del Estado en el hecho. Si bien el tratamiento judicial de estos casos no suele ser caratulado de esta manera, optamos por esta clasificación hasta tanto existan comprobaciones fehacientes de lo sucedido en el hecho. Esta categoría nos permite además visibilizar casos en que las fuerzas de seguridad estarían implicadas por acción u omisión en la desaparición física de una persona" 15 .

\footnotetext{
${ }^{13}$ Fuentes: http://www.infojusnoticias.gov.ar/provinciales/cordoba-el-rubio-del-pasajenunca-volvio-del-baile-270.html, http://www.infojusnoticias.gov.ar/nacionales/actos-ymarchas-a-tres-anos-de-la-desaparicion-del-rubio-del-pasaje-7519.html. En: http://unc2.unc.edu.ar/extension/vinculacion/observatorio-ddhh/mapa-violencia. Última consulta: 03/03/2017.

${ }^{14}$ Especialmente el Colectivo de Jóvenes por Nuestros Derechos, las organizaciones nucleadas en la Mesa Provincial por los Derechos Humanos de Córdoba y diversos espacios políticos y culturales de la UNC, como el mismo Observatorio de Derechos Humanos.

15 http://unc2.unc.edu.ar/extension/vinculacion/observatorio-ddhh/mapa-violencia. Última consulta: 20/07/2017.
} 
La prevalencia y el sostenimiento a lo largo del tiempo del hecho de la desaparición en diversos espacios sociales, académicos y políticos fueron legitimando la disputa de sentidos orientada a trascender la nominación ligada a una violencia horizontal, privada -incluso designada como ajuste de cuentas ${ }^{16}$ - que fuera reforzada por el juicio y por la posición de algunos medios hegemónicos. Más allá de cualquier dictamen judicial, la desaparición, como muerte inconclusa (Da Silva Catela, 1998), (re)actualiza constantemente la lucha y vuelve a colocar el acento sobre la responsabilidad de las agencias del Estado. Al mismo tiempo, podríamos decir con Lacerda que la etapa del duelo y del luto se prolongan con un propósito político y que esto frustra "la expectativa social de que la vida de los familiares sea retomada luego de un período legítimo de suspensión de sus actividades cotidianas" (2014: 69).

En este contexto, la inclusión del caso de Facundo en la muestra itinerante "Entre altares y pancartas" representó ciertamente algunos retos. Por un lado, porque tanto las organizaciones que participaban como los investigadores apostábamos a la visibilización de su ausencia, de su ocultamiento, como una responsabilidad del Estado, de modo que debimos ampliar nuestra mirada hacia una concepción de violencia institucional más abarcativa que pudiera contener la complejidad de todos los $\operatorname{casos}^{17}$. Por otra parte, y como señalaba en la introducción, uno de los propósitos de la muestra reside en dar a conocer las prácticas de conmemoración desarrolladas por los familiares en torno a la construcción de altares y de grutas. De hecho, la muestra constaba hasta ese momento de tripticos que recreaban estas espacialidades "sacralizadas". ¿Cómo incluir entonces a un desaparecido sin altar, sin gruta, sin tumba? ¿Cómo mostrar la dolorosa experiencia de su ausencia?

Cuando en aquella visita a la casa de Viviana, a los pocos meses de la desaparición de Facundo, le pedimos tomar fotografías para la muestra, ella acomodó la gigantografía de su hijo en una de las esquinas de la habitación y mientras nos hablaba la miraba fijamente, como

\footnotetext{
16 Se puede visitar, a modo de ejemplo: http://www.cadena3.com/post_ampliadomobile.asp?post $=1320658$ titulo=Confesion-demenor-no-incide-en-causa-del-Rubio-del-Pasaje\&resw=13668resh=728. Última consulta: 20/07/2017.

${ }^{17}$ Como antropólogos y antropólogas privilegiamos en la muestra la noción nativa de "violencia institucional" que, hasta ese momento, se restringía a denunciar la violencia policial. Para profundizar sobre estos debates, ver: Perelman y Trufó, 2016.
} 
acariciándola. Esa misma pancarta, que reconocimos inmediatamente por estar presente en diversas marchas y escraches, lo muestra haciendo señas con las manos en referencia al pasaje donde vivía, tal como lo hace La Mona en cada baile ${ }^{18}$.

\section{Imagen 1. Viviana con la pancarta del Rubio en su habitación}



Fuente: Muestra "Entre altares y pancartas".

${ }^{18}$ El cantante de cuarteto La Mona Giménez, ha inventado señas para cada uno de los lugares y barrios de donde provienen sus fans y las realiza en cada baile a pedido de su público. 
Imagen 2. En las calles de la ciudad, en la marcha organizada a un año de su desaparición

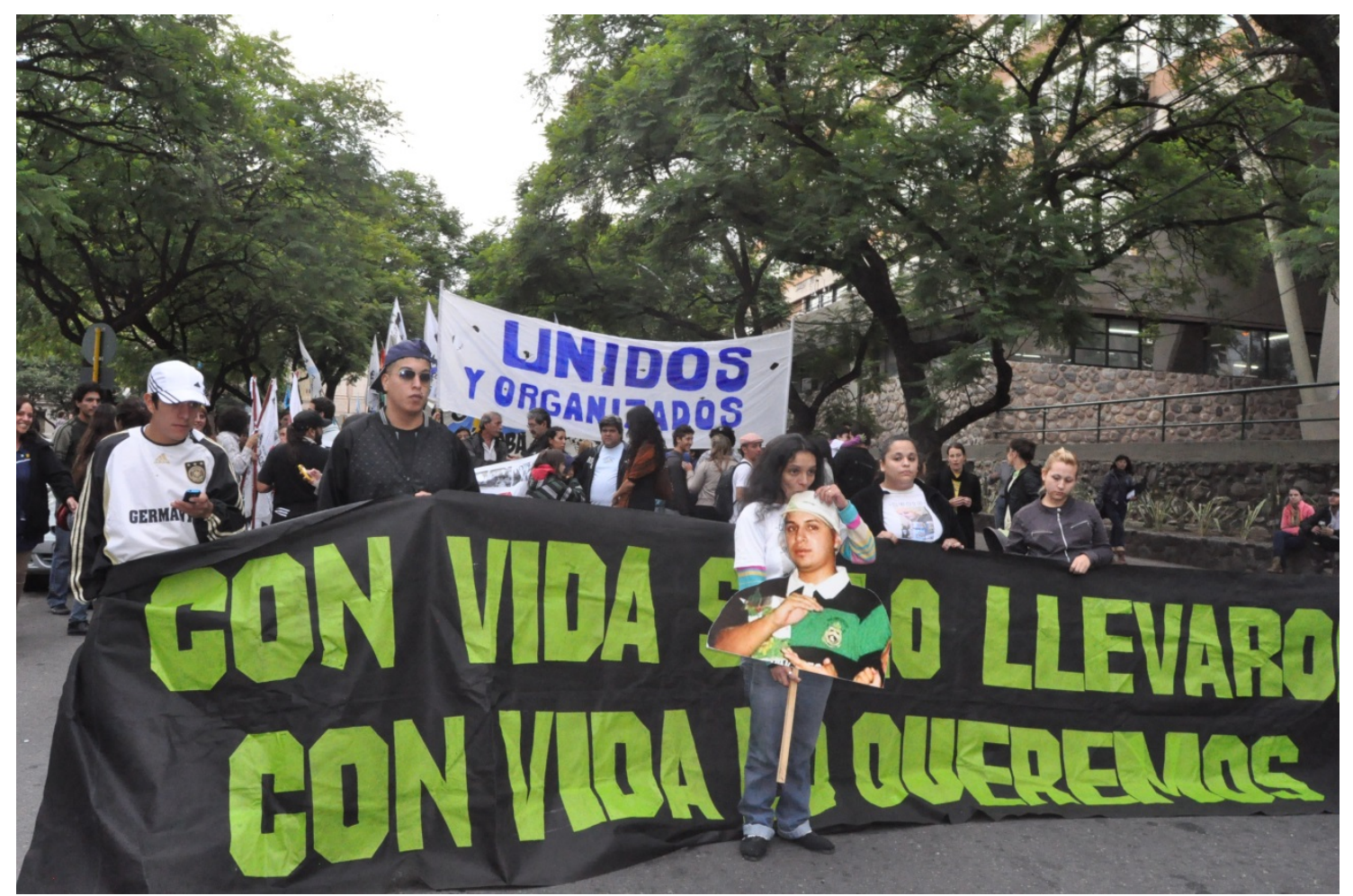

Fuente: Muestra "Entre altares y pancartas".

Si bien el lugar que ocupan objetos como estos se vincula con los ciclos de visibilidad y de denuncia ${ }^{19}$, en tanto son preparados para responder a la necesidad de acelerar las causas judiciales o bien para conmemorar las fechas clave, y pueden estar asociados a los desplazamientos entre el "caso particular" y el "interés general" (Boltanski, 2000), el recorrido de esta pancarta marca otras cuestiones que lo exceden. Tal como podemos observar en las fotografías y como lo vivencié en su casa, esa imagen marca para Viviana el poder de la presencia del Rubio. $y$, en ese mismo acto, denuncia la significatividad de su ausencia.

Junto a Viviana, y luego de algunos debates, decidimos incorporar las fotografías de la habitación de Facundo y colocar debajo de esas

\footnotetext{
${ }^{19}$ María Pita, en relación con casos de violencia institucional — sobre todo policial- de Buenos Aires, llama tecnología manifestante "a este conjunto de técnicas y prácticas asociadas que suponen un saber y un dominio de sus formas y fuerzas en términos de efectos productivos (visibilidad de demandas)" y que no tienen reglas sistemáticas (2004: 439-440).
} 
imágenes una silla vacía, en alusión tanto a esa ausencia como a la espera de su familia.

\section{COMO FAMILIA}

Poco tiempo después del desarrollo del juicio, me encontré con Viviana y con otra compañera para entrevistarla, en sus palabras, como militante. En esa ocasión, Viviana apeló a la obligatoriedad del lazo para explicar su posicionamiento, nos decía que hizo "lo que haría cualquier madre" y que, en todo caso, es la misma militancia que tenía su padre con el comedor en Entre Ríos, su provincia natal, y la que tienen tantas otras personas anónimas.

Por aquellos conocidos que tenía entre los miembros de H.I.J.O.S ${ }^{20}$ y con la $\mathrm{Mesa}^{21}$ es que se fue creando un vínculo más estrecho con los organismos. Según nos cuenta, Viviana ya había participado de otras actividades realizadas por H.I.J.O.S, entre las que recuerda especialmente un escrache organizado para denunciar a un represor en cercanías de su casa y en el que también había estado presente el mismo Facundo. Como lo referiré más adelante, Viviana tiene un hermano y una cuñada desparecidos durante la última dictadura argentina. Ella venía apoyando a su otro hermano en la búsqueda de los cuerpos y de una posible sobrina.

Los días posteriores a la desaparición de su hijo, Viviana se acercó a "la Mesa, para contar lo que estaba pasando". A partir de allí se comenzaron a articular numerosas acciones conjuntas que incluyeron al Archivo Provincial de la Memoria (APM) ${ }^{22}$ ubicado en el ex centro clandestino de

\footnotetext{
${ }^{20}$ H.I.J.O.S, Hijos e Hijas por la Identidad y la Justicia contra el Olvido y el Silencio, funciona en Córdoba desde 1995. Según señalan en su página web, "Somos una organización de derechos humanos, desde 1995 en lucha por la memoria, la verdad y la justicia, por el juicio y castigo y la Condena Social". Más información en: https://esla.facebook.com/hijoscba/. Última consulta: 02/02/2017.

${ }^{21}$ Los integrantes definen a la Mesa de Trabajo por los Derechos Humanos Córdoba como un "movimiento popular", conformado por diversas organizaciones gremiales, sociales, culturales, entre las que se encuentran Familiares e H.I.J.O.S., y en cuya sede se reúnen todos los jueves. Más información en: https://www.facebook.com/mesadetrabajo.porlosderechoshumanosdecordoba/. Última consulta: 03/02/2017.

${ }^{22}$ Fue creado por Ley Provincial de la Memoria 9286 aprobada unánimemente por la Legislatura de Córdoba en marzo de 2006. Alli alojaron "dependencias policiales ligadas a la persecución y represión social, política, cultural y sindical; entre ellas el 'Departamento de Informaciones D2', que fue un engranaje central en la instauración del terrorismo de Estado en la provincia de Córdoba". Información disponible en: 
detención conocido como D2, donde algunos integrantes de estos organismos trabajan, coordinadas generalmente por Emiliano ${ }^{23}$. Desde esos lazos establecidos es que también accedió al patrocinio de Claudio Orosz, un reconocido abogado penalista especialista en derechos humanos, y que ha sido abogado querellante en las causas por violaciones a los derechos humanos durante el terrorismo de Estado.

Ahora bien, a esas redes Viviana las presenta de una forma muy particular. Durante una nueva inauguración de la muestra en Tribunales Il de la ciudad de Córdoba a comienzos de 2017, Viviana nos dice a los presentes: "hace mucho tiempo que yo elegí a los chicos de la Mesa como mi familia, ellos son mi familia".

La apelación a la figura de la familia surge constantemente en sus apariciones públicas. El discurso que dio durante la marcha del 24 de marzo de 2013, convocada por los organismos a poco más de un año de la desaparición de Facundo, anuda estos entramados que intento problematizar. Desde un lugar privilegiado como una de las oradoras, Viviana tomó el micrófono con firmeza y expresó:

Desde la familia de Facu, a un año y un mes de su
desaparición, denunciamos que no hay avances. Que solo se
ha buscado. No hay nada, solo más mentiras y dilaciones. El
gobernador no nos ha recibido, siendo el máximo responsable
de que haya un desaparecido en Córdoba y quien debería dar
las explicaciones correspondientes a la familia de por qué es
posible que haya desaparecido sin tener el apoyo del poder
político... A esta policía cordobesa que por acción u omisión -
yo diría más que por acción es responsable- le queremos
decir que a Facu lo vamos a encontrar aunque me cueste la
vida [aplausos]. Hace mucho dijimos "Nunca Más", no solo
estamos con los 30.000 desaparecidos... Hermano querido,
donde quiera que estés, Marcos, te quiero. Nati. Sin Facundo,
sin Luciano, sin Julio, sin Yamila y sin tantos otros no hay
Nunca Más.

Ella no habla en su nombre como madre de Facundo. Lo hace a título de la familia. Es desde allí que se presenta e interpela al gobierno preguntando qué pasó con Facundo. Viviana, separada, tiene además un

http://www.apm.gov.ar/apm/portada. Última consulta: 03/03/2017. Actualmente funciona un sitio de memoria y un archivo.

${ }^{23}$ Emiliano, hijo de ex presos políticos, integra el área de Violencia Institucional de H.I.J.O.S. y coordina la Mesa de Trabajo por los derechos humanos. Trabaja además en el Archivo Provincial de la Memoria (APM). 
hijo en el extranjero y una hija fallecida en un accidente de tránsito a los pocos años de vida - muerte a la que no refiere como denunciable-. Este nosotros inclusivo consigue incorporar en su reclamo público especialmente a la hija de Facundo, por entonces de apenas unos meses de vida. Pero además, esa familia, podría comenzar a integrar también los lazos que se fueron estrechando con los de la Mesa.

Establecer un puente, como Viviana lo hace, entre pasado y presente, desde la apelación al Nunca Más, desvela su propia trayectoria. Luego de mencionar a los 30.000 desaparecidos, en su discurso Viviana individualiza a dos de ellos y les habla: a Marcos y a Nati. Marcos, su hermano, desaparecido durante la dictadura en el centro clandestino EI Pozo de Banfield. Nati, su cuñada, embarazada de seis meses, desaparecida en la Escuela de Mecánica de la Armada (ESMA). Es decir que con Facundo la figura de la desaparición se hace nuevamente presente en su historia familiar. La alusión que hace Viviana al Nunca Más no es entonces meramente alegórica, sino que responde a su propia biografía y a los modos legitimados de devenir víctima en las redes que se tejen en torno a su caso.

En alusión a estos lazos, Viviana me contaba cómo es que las vivencias, recuerdos y dolores del pasado se vivifican sobre su presente y adquieren una nueva densidad:

Mi hermano era del primer matrimonio de mi papá. Pero eran
mis hermanos, venian siempre a casa. Mi hermano y su novia
eran maestros rurales y se habian ido a Misiones. De ahí
decidieron ir a estudiar a La Plata para volver luego. y
militaban... Tenian un comedorcito, una copa de leche. Pero
desaparecen. Ella estaba embarazada de seis meses. Estamos
esperando a ver si algún día se encuentra ese hijo de ellos.
Cuando desaparecen ellos en La Plata, mi papá y yo
estábamos en la casa, pero nos escondimos. Nosotros
escuchamos todos los gritos cuando se los llevaron. Nos
escondimos porque ellos nos insistieron, nos metimos
adentro del placard. Si escuchamos mucho los gritos de ella.
Yo los volví a recordar cuando desapareció Facu. Cuando pasó
eso, me vino todo de nuevo a la cabeza.

La apelación a esa familia viene acompañada entonces de genealogías y de repertorios en torno a la militancia, pero también de lazos 
construidos por afinidades y elecciones ${ }^{24}$, y especialmente por experiencias compartidas.

Tal como decía al comienzo de este texto, desde la literatura académica se viene reflexionando sobre la eficacia del principio de adhesión basado en la familia. La apelación a la condición de "familiar" constituye sin dudas uno de los principios centrales sobre los cuales se estructuran distintas agrupaciones y movimientos.

Ahora bien, podemos decir que la familia resulta vivida, movilizada y agenciada en el devenir militante de Viviana, más allá de la consanguinidad. La familia no es una mera apelación, ni lo es exclusivamente al menos- en términos de eficacia. Su caso nos muestra que los vínculos que se tejieron y el espesor que adquirieron en su lucha, no solo se entienden a partir de las relaciones entabladas antes de lo sucedido con su hijo y de los repertorios heredados, sino también respecto de cómo fueron movilizados tras la desaparición del Rubio.

Podemos considerar también en este sentido que el modo en el que se produjo el nacimiento de Familiares y Amigos de Facundo en el marco del proceso judicial expresa cierta eficacia de aquel mecanismo por el cual se extienden las imágenes simbólicas de la familia hacia otros colectivos, potenciando los puentes con el resto de la comunidad. Recordemos que la agrupación nuclea especialmente a jóvenes universitarios de diversos extractos políticos. Su exposición pública bajo el lazo familiar y vincular la aleja de las sospechas que recaen sobre los grupos de otro orden -en los que podrían dejar de prevalecer el desinterés y la pureza involucrados en las demandas-, es decir, sobre aquellos que se reúnen por "otros motivos que no son vistos como igualmente transparentes o legítimos" (Jelin, 2007: 45), conformación que aseguraría además la proximidad con las experiencias de dolor que muchas veces aparecen como de carácter intransferible (Villarreal, 2016).

Si bien los procesos de extensión de la metáfora pueden otorgar un paraguas más amplio, abarcativo y relativamente consagrado que consigue incluir expresiones diversas, podrian invisibilizar a la vez las pertenencias partidarias o a aquellos ciudadanos que no necesariamente buscarían hacer del parentesco una forma de distinción

\footnotetext{
${ }^{24}$ Cabe considerar que Viviana es hija adoptada y, como dije, colabora con un hermano en la lucha para encontrar a sus familiares desaparecidos.
} 
pública (Vecchioli, 2005). Aun para el caso de Viviana cabe advertir cómo el agenciamiento del lenguaje del parentesco para la militancia de los derechos humanos no se encuentra exento de tensiones y disputas, en especial si situamos la mirada sobre aquellos principios hegemónicos destinados a los sectores populares. Veamos a continuación.

\subsection{Facu como desaparecido}

Las marcas territoriales pueden ser interesantes para pensar en estas tensiones, en la medida en que tienden a cristalizar las jerarquías sociales, según intento problematizar aquí. Ludmila da Silva Catela, por entonces directora del APM, analizó en un texto académico los debates que se produjeron en torno a "lo que merece ser recordado" en este ex centro clandestino de detención emplazado en la zona céntrica de la ciudad de Córdoba. "¿Hay lugar allí para los asesinados? ¿Los ajusticiados dentro de las filas guerrilleras también pueden tener su espacio?" (2014: 5), se pregunta. Asimismo, reconoce que "los debates más intensos se dan con las categorías de personas muertas que no están definidas claramente $o$ sobre las que pesan diversas interpretaciones familiares en torno a cómo y dónde deben ser recordadas en relación al origen de su muerte" (ibídem).

La incorporación o no de la imagen del Rubio entre las 700 fotografías de desaparecidos y asesinados de la provincia de Córdoba durante la dictadura colgadas sobre el Pasaje Santa Catalina todos los jueves fue un tema de discusión entre los integrantes del Archivo, muchos de ellos compañeros de militancia de Viviana. Como sostiene Da Silva Catela, estos debates "revelan que las demandas que se construyen en función de la definición sobre qué se incluye y qué se excluye giran en relación con una noción central y general que es la de 'víctimas'" (ibídem: 37 ).

Según su relato, finalmente se decidió incluir sobre la fachada principal del edificio una imagen del Rubio. La gigantografía lo mostraba de cuerpo entero y aparecía claramente diferenciada del memorial de las fotos. Esta intervención sobre las paredes fue al poco tiempo quitada por empleados de la municipalidad de Córdoba. A partir de ese momento, el área de educación del Archivo colocó un cartel que decía "en este lugar estaba la foto de Facundo Rivera Alegre. La Municipalidad mandó a arrancarlo para que el Pasaje esté 'limpio' en el Día de la Patria" (ibídem: 37). 
Parece oportuno volver a plantearnos en este recorrido cómo es que se experimentan los casos que incomodan toda vez que interpelan las fronteras y las divisiones establecidas, por ejemplo, entre lo sagrado y lo profano, entre el pasado y el presente, entre clases sociales, y expresan con todo su poder conflictos morales y políticos. Esos conflictos se materializan en las luchas por la significación de un espacio público altamente valorado por su ubicación y simbolismo.

Los debates dados en torno a la inclusión de Facundo en el memorial pueden revelarnos entonces tanto las interpretaciones sobre "lo que merece ser recordado" (ibídem) según las formas y contextos de desaparición, según las trayectorias implicadas, o bien en términos de qué concepciones políticas pueden pensarse las desapariciones. Pero al mismo tiempo nos develan una inclusión. Facundo se convierte así en emblema de la desaparición en democracia, y tiene su lugar en un espacio consagratorio de memorias.

\subsection{Un choro menos}

En los últimos años he venido trabajando sobre el rol privilegiado que se les adjudica a las madres para reclamar por la muerte de los jóvenes vinculados a contextos de violencia. He sugerido que esa legitimidad colisiona con otro precepto -más normativo aún para los sectores populares - según el cual la responsabilidad social de la moral del hijo recae sobre la madre, de modo que si el hijo es sospechado de inmoral, por carácter transitivo también lo será la madre, recordándole de esta forma los deberes incumplidos según su rol. Es decir, que la apelación política basada en esa ligazón, según los casos, podría tender a reforzar paradójicamente las mismas acusaciones morales que pretenderían trascender, en la medida en que es precisamente a las madres a quienes se les adjudica la responsabilidad social de la crianza moral de sus hijos. Son las madres las que deberian garantizar que sus hijos sean "personas de bien", como se arguye en términos nativos (Bermúdez, 2016).

Las acusaciones que ha recibido Viviana condensadas en la expresión "un choro menos", no se diferencian de tantas otras que he escuchado a lo largo de mi trabajo de campo. "Por algo será", "Algo habrán hecho" o "Dime con quién andas..." se enuncian para dar cuenta del carácter "merecido" de cierto conjunto de muertes, reactualizando y resignificando estigmatizaciones enraizadas en profundos entramados históricamente configurados en torno a la pobreza (Guber, 1999). 
Si bien tener tres desaparecidos entre sus parientes convierte a Viviana en merecedora de una especie de respeto mayor por el dolor acumulativo que esta experiencia puede provocarle, en ciertos contextos también la sumergen en cierto estado de sospecha. Según he demostrado, en la moralización de la víctima reside la operación privilegiada por gran parte de los familiares para intentar contrarrestar las acusaciones y legitimar su intervención y reconocimiento públicos. “Mi hijo era de buen corazón, él trabajaba, siempre se llevó bien con todos", son argumentos que permiten anclar las reputaciones afectadas a "comunidades morales" (Bailey, 1971) y que pueden sustentar el carácter inmerecido de las muertes.

Las autoras con las que vengo dialogando también han advertido sobre aquel trabajo moral efectuado por las madres de los desaparecidos de la última dictadura argentina, especialmente en relación con la militancia de sus hijos (Da Silva Catela, 2006; Vecchioli, 2005; Jelin, 2010; entre otras). Las madres han buscado exaltar de sus hijos algunos valores como la solidaridad, el sentido de justicia y el amor por los demás, esto es, "valores morales trascendentes" (Vecchioli, 2005) y no como miembros de agrupaciones políticas y sociales con intereses y posicionamientos particulares. En esta misma línea, Jelin (2010) advierte que lo que las Madres estaban denunciando eran crímenes contra la familia, intentando transmitir al mismo tiempo una imagen de "buen hijo" del joven desaparecido y de una vida familiar "normal".

Ahora bien, estas estrategias asociadas a silenciamientos $u$ opacidades ¿pueden ser pensadas del mismo modo para otras víctimas? Desde el comienzo de su aparición pública, Viviana sostuvo una postura poco frecuente. En la primera marcha que se organizó en torno a la desaparición de Facundo frente a la sede del gobierno provincial, Viviana expresaba: "No importa si en todo caso mi hijo era o no un delincuente, no tienen por qué hacerlo desaparecer". He presenciado al mismo tiempo cómo Viviana ha acompañado la lucha de otras madres, incluso pertenecientes a organizaciones diversas y enfrentadas entre sí, denunciando los supuestos sociales hegemónicos que colocan la muerte y la desaparición en términos de "merecimientos".

Aun a pesar de estos posicionamientos fundados en la retórica de los derechos humanos, aquellos prejuicios que se dirigian contra Facundo $-y$, por tanto, contra su madre-, fueron solidificados en buena parte de la ciudadanía cordobesa como consecuencia del resultado del juicio. De 
modo que las opacidades, los silenciamientos y también aquellas retóricas, resultan operaciones complejas de ser movilizadas por quienes encarnan supuestos apriorísticos sobre la pobreza, asociados comúnmente a la inmoralidad (Guber, 2007; Blázquez, 2008). Al echar luz sobre estas perspectivas es que surge el interés por cuestionar tanto la marcada tendencia a la demonización de los sujetos de sectores populares, como también a su romantización - sostenida incluso desde la academia-, concebida como aquella búsqueda idealista de promesas al pensarlos como los nuevos actores sociales.

\section{ReFLEXIONES FINALES}

Familiares, víctimas, comunidades de sangre y activismo se configuran como dimensiones clave para comprender la consagración de movimientos de derechos humanos en América Latina -especialmente en Argentina- y su centralidad en la esfera pública.

En este texto hemos visto cómo Viviana, madre de Facundo, consigue legitimarse -especialmente en determinados espacios y contextoscomo activista familiar o, en sus palabras, como "militante". Según el recorrido que he propuesto, la movilización del lenguaje del parentesco habilitó articulaciones entre pasado y presente - condensada en la frase emblema: "Sin Facundo no hay Nunca Más"-, aunque no por ello ha resultado exenta de tensiones, disputas y desigualdades.

Me interesa resaltar especialmente cómo no solo la desaparición -y las disputas de sentidos en torno a ella-, sino también el estatus del Rubio como desaparecido se conjuraron en el centro de la escena. Facundo, como tantos otros, era un joven que reproduce y hace clase: su pelo teñido de rubio platinado, cuartetero, trabajador de las obras de construcción, detenido por "contravenciones". Las comparaciones - por veces inevitables - entre víctimas y entre tipos de desaparecidos se invocaron en distintos espacios y situaciones: en los medios de comunicación, en las diversas instancias del juicio, en la creación del mural en el APM e incluso en la incorporación de las imágenes en la Muestra.

Ahora bien, considero que las articulaciones fueron posibles porque la familia -experimentada desde lazos de consanguinidad, afinidades, afectos, experiencias y horizontes comunes - no nos remite aquí a una unidad preestablecida y -siempre- esencializada, sino que puede 
(re)crearse con cierto dinamismo. Es decir que, inspirada en Calhoun cuando refiere a la identidad en la protesta (1999), la familia para Viviana se va conformando en la misma lucha. Cabría preguntarnos entonces si para actuar eficazmente, esas víctimas deben ser reconocidas como pertenecientes a alguna familia. Y esto nos ubica nuevamente en la discusión sobre las exclusiones y las fronteras que las categorías de parentesco instituyen (Bourdieu, 2007), y que, aunque dúctiles, pueden resultar poco accesibles para otras personas, movimientos o luchas ${ }^{25}$. Pienso especialmente en quienes, con trayectorias diferentes a las de Viviana, deben efectuar simultáneamente todo un trabajo político, social y simbólico para acceder a la condición de víctima, a través de la limpieza moral (Vianna y Farias, 2011; Bermúdez, 2016), de la denuncia de la crueldad (Bermúdez, 2016), de las narrativas del dolor (Lacerda, 2014), de la impugnación de la condición de seres matables (Pita, 2010), para tornar las muertes y desapariciones en dramas sociales. Si seguimos el derrotero de otro conjunto de casos, vemos que pocos han conseguido notoriedad pública o incluso posiciones de reconocimiento en estas $u$ otras familias.

\section{BiBLIOGRAFÍA}

Abreu Filho, O. (1982). Parentesco e Identidade Social. Anuário Antropológico, 80. Fortaleza: Edições UFC, y Río de Janeiro: Tempo Brasileiro Autor.

Araújo, F. A. (2007). Do luto à luta: a experiência das Mães de Acari. (Tesis de maestria inédita). Instituto de Filosofia e Ciências Sociais, Universidade Federal do Rio de Janeiro (UFRJ), Río de Janeiro.

Bailey, F. G. (1971). Gifts and Poison, the politics of reputation. Oxford: Basil Blackwell.

Bermúdez, N. (2011). y los muertos no mueren... una etnografía sobre clasificaciones, valores morales y prácticas en torno a muertes violentas (Córdoba, Argentina). Saarbrücken, Alemania: Editorial Académica Española.

Bermúdez, N. (2014). Moralidades de la inseguridad. Entramados locales y principios de adhesión política en casos de muertes violentas. En N. Bermúdez y M. E. Previtali (Coords.), Merodear la ciudad. Miradas

\footnotetext{
${ }^{25}$ Como lo señala Bourdieu, "el beneficio simbólico es tanto más grande cuanto más alejadas estén las personas entre las cuales se establece la relación" (2007: 267).
} 
antropológicas sobre espacio urbano e inseguridad en Córdoba (pp. 105-126). Córdoba: Ediciones del Idacor-Conicet.

Bermúdez, N. (2016). 'De morir como perros' a 'me pinto sólo cuatro uñas'. Una mirada antropológica sobre crueldad, moralidad y política en muertes vinculadas a la violencia institucional en Córdoba (Argentina). Publicar. En Antropología y Ciencias Sociales, XIV(XX), 928.

Blázquez, G. (2008). Negros de alma. Raza y procesos de subjetivación juveniles en torno a los Bailes de Cuarteto (Córdoba, Argentina). Estudios en Antropología Social, 1(1), 6-34.

Boltanski, L. (2000). El amor y la justicia como competencias: tres ensayos de sociología de la acción. Buenos Aires: Amorrortu Editores.

Bourdieu, P. (2007/1980). Los usos sociales del parentesco. En El sentido práctico (pp. 257-316). Argentina: Siglo XXI.

Brocca, M. et al. (2013). Policía, seguridad y código de faltas. Informe Mirar tras los muros. Situación de los derechos humanos de las personas privadas de la libertad en Córdoba, segunda parte. Córdoba: Comisión y Archivo Provincial de la Memoria, UniRío, Universidad Nacional de Córdoba.

Calhoun, C. (1999). El problema de la identidad en la acción colectiva. En I. Auyero (Ed.), Caja de herramientas (pp.77-114). Buenos Aires: Universidad Nacional de Quilmes.

Claps, L. (2007). Representaciones y discursos sobre la violencia: los casos de Cofavi y Madres del Dolor. En Actas de las XI Jornadas Nacionales de Comunicación. Mendoza.

Coria, A., y Etchichury, H. (2010). Código de Faltas Córdoba. Comentarios a partir de la respuesta a un pedido de informe legislativo. Recuperado de: http://codigodefaltasblogspot.com.

Da Silva Catela, L. (1998). Sin cuerpo, sin tumba. Memorias sobre una muerte inconclusa. Historia, Antropología y Fuentes Orales, 20, 87104.

Da Silva Catela, L. (2001). De eso no se habla. Cuestiones metodológicas sobre los silencios en entrevistas a Familiares de desaparecidos políticos. Historia, Antropología y Fuentes Orales, 24, 69-75.

Da Silva Catela, L. (2006). Desaparición, violencia política y dictadura en Argentina. Mapas de la violencia, políticas y ciclos de las memorias. En Memoria e Historia (pp. 51-78). Guatemala: AVANCSO. 
Da Silva Catela, L. (2008). Derechos humanos y memoria. Historia y dilemas de una relación particular en Argentina. Teoria e Cultura, 3(1/2), 9-20.

Da Silva Catela, L. (2014). "Lo que merece ser recordado...". Conflictos y tensiones en torno a los proyectos públicos sobre los usos del pasado en los sitios de memoria. Clepsidra. Revista Interdisciplinaria de Estudios sobre Memoria, 2, 28-47.

Filc, J. (1998). Entre el parentesco y la política. Buenos Aires: Biblos.

Fonseca, C. (2005). La clase social y su recusación etnográfica. Etnografias Contemporáneas, 1, 117-138.

Gingold, L. (1996). Control Ciudadano y descontrol policial. En Jelin, E. Gingold L., et al. (Eds.), Vida cotidiana, control institucional en la Argentina de los '90 (pp. 137-170). Buenos Aires: Nuevo Hacer.

Guber, R. (1999). El Cabecita Negra o las categorías de la investigación etnográfica en la Argentina. Revista de Investigaciones Folclóricas, 14, 108-144.

Guber, R. (2007). Identidad social villera. En M. Boivin, A. Rosato y V. Arribas (Eds.), Constructores de otredad. Una introducción a la antropología social y cultural (pp. 151-165). Buenos Aires: Antropofagia.

Jelin, E. (2005). Exclusión, memorias y luchas políticas. En D. Mato (Comp.), Cultura, política y sociedad, perspectivas latinoamericanas (pp. 219239). Buenos Aires: Clacso.

Jelin, E. (2007). ¿Víctimas, familiares o ciudadano/as? Las luchas por la legitimidad de la palabra. Cadernos Pagu, 29, 37-60.

Lacerda, P. (2014). O sofrer, o narrar, o agir: dimensões da mobilização social de familiares de vítimas. Horizontes Antropológicos, 42, 49-75.

Ortner, S. (1995). Resistance and the Problem of Ethnographic Refusal. Comparative Studies in Society and History, 37(1), 173-193.

Perelman, M., y Trufó, M. (2016). Violencia institucional, tensiones actuales de una categoría política central. Ciencias Sociales, 92, 14-22.

Pita, M. (2004). Violencia policial y demandas de justicia: acerca de las formas de intervención de los familiares de víctimas en el espacio público. En S. Tiscornia (Comp.), Burocracias y violencia: estudios de antropología juridica (pp. 435-464). Buenos Aires: Antropofagia/Facultad de Filosofía y Letras, Universidad de Buenos Aires.

Pita, M. (2005). Mundos morales divergentes: los sentidos de la categoría familiar en las demandas de justicia ante casos de violencia policial. En S. Tiscornia y M. Pita (Eds.), Derechos humanos, tribunales y 
policias en Argentina y Brasil (pp. 205-235). Buenos Aires: Antropofagia.

Pita, M. (2010). Formas de morir y formas de vivir: el activismo contra la violencia policial. Buenos Aires: Ediciones del Puerto/CELS.

Rebollar, A. (2013). De madre doliente a Madre Dolor. La construcción de una denuncia pública y de una militancia. $X$ Jornadas de Sociología. Buenos Aires: Facultad de Ciencias Sociales, Universidad de Buenos Aires.

Sarti, C. (2009). Corpo, violência e saúde: a produção da vítima. Sexualidad, Salud y Sociedad. Revista Latinoamericana, 1, 89-103.

Schneider, D. (1968). American Kinship: A Cultural Account. Nueva Jersey: Pretice-Hall, Inc., Englewood.

Segato, R. (2013). La escritura en el cuerpo de las mujeres asesinadas en Ciudad Juárez. Territorio, soberanía y crímenes de segundo estado. Buenos Aires: Tinta Limón.

Sikkink, K. (1999). La red internacional de derechos humanos en América Latina: surgimiento, evolución y efectividad. En E. Jelin y E. Hershberg (Coords.) Construir la democracia: derechos humanos, ciudadanía y sociedad en América Latina (pp. 59-84). Venezuela: Nueva Sociedad.

Tiscornia, S. (2004). Burocracias y violencia: Estudios de antropología jurídica. Buenos Aires: Antropofagia/Facultad de Filosofía y Letras, Universidad de Buenos Aires.

Tiscornia, S. (2005). Límites al poder de policía. El activismo del derecho internacional de los derechos humanos y el caso de Walter Bulacio ante la Corte Interamericana de Derechos Humanos. En S. Tiscornia y M. Pita (Eds.), Derechos Humanos, tribunales y policias en Argentina y Brasil. Estudios de antropología jurídica (pp. 43-69). Buenos Aires: Antropofagia.

Vianna, A., y Farias. J. (2011). A guerra das mães: dor e política em situações de violência institucional. Cadernos Pagu, 37, 79-116.

Vecchioli, V. (2005). La nación como familia. Metáforas políticas en el movimiento argentino por los derechos humanos. En S. Frederic y G. Soprano (Comps.), Cultura y Política en Etnografías sobre la Argentina (pp. 1-22). Buenos Aires: Universidad Nacional de Quilmes.

Villarreal, A. (2016). Al dolor lo llevamos nosotros. Una etnografía en torno a la muerte, política y emociones en Capilla del Monte (Córdoba). (Tesis 
de licenciatura inédita). Facultad de Filosofía y Humanidades, Universidad Nacional de Córdoba, Córdoba.

Zaluar, A. 1999. Violencia e Crime. En S. Miceli (Comp.), O que ler na ciência social brasileira (1970-1995) (pp. 13-107). Brasil: Sumaré, Anpocs, Capes.

Zenobi, D. (2014). Familia, política y emociones. Las víctimas de Cromañón entre el movimiento y el Estado. Buenos Aires: Antropofagia. 